\title{
FECAL GLUCOCORTICOID LEVELS OF ENDANGERED SAN JOAQUIN KIT FOXES (VULPES MACROTIS MUTICA) IN NATURAL AND URBAN HABITATS
}

\author{
Julia L. Nelson ${ }^{1,2}$, Scott Creel ${ }^{2}$, and Brian L. Cypher ${ }^{1,3}$
}

\begin{abstract}
Animals that are exposed to environmental stressors may experience chronically elevated glucocorticoid (GC) levels, which can lead to deleterious effects such as immune and reproductive system suppression. Such effects are of special concern in rare species. We measured fecal GC concentrations in endangered San Joaquin kit foxes (Vulpes macrotis mutica) to assess stress responses in natural and urban habitats. Basal GC levels were significantly higher $(P<$ $0.01)$ among urban foxes $(5.3 \pm 2.2 \mathrm{ng}$ cortisol/g dry feces; $n=32)$ than among foxes in natural habitats $(4.7 \pm 0.5 \mathrm{ng}$ cortisol/g dry feces; $n=179$ ). In the natural habitat, potential stressors included predation risk, particularly in areas with shrubs where coyote (Canis latrans) abundance was higher. In the urban habitat, the primary stressors were anthropogenic disturbances (e.g., human activity, vehicles). Foxes in natural habitats exhibited acute stress responses when trapped, but exhibited similar mean GC levels between areas of high and low predation risk, suggesting adaptation to the presence of coyotes. Urban foxes did not exhibit acute responses when trapped, suggesting adaptation to the presence of humans. Stress responses based on GC levels indicated that foxes in both natural and urban habitats are habituated to the primary stressors in each habitat, thereby mitigating chronic stress.
\end{abstract}

Resumen.-Los animales que están expuestos a estrés ambiental pueden experimentar niveles muy elevados de glucocorticoides (GC), los cuales pueden provocar efectos nocivos, tales como la supresión del sistema inmunológico y reproductivo. Estos efectos especialmente preocupantes en especies raras. Medimos concentraciones GC en muestras de heces de crías del zorro de San Joaquín (Vulpes macrotis mutica), en peligro de extinción, para evaluar la respuesta al estrés en hábitats naturales y urbanos. Los niveles basales de zorros urbanos GC fueron significativamente mayores $(P<0.01)$ $(5.3 \pm 2.2 \mathrm{ng}$ cortisol $/ \mathrm{g}$ dry feces; $n=32)$ que de los zorros en zona natural $(4.7 \pm 0.5 \mathrm{ng}$ cortisol/g dry feces; $n=179)$. En su hábitat natural, las posibles fuentes de estrés incluyen el riesgo de depredación, especialmente en las áreas arbustivas donde la presencia de coyote (Canis latrans) era mayor. En el hábitat urbano los principales factores estresantes fueron los disturbios antropogénicos (es decir, la actividad humana, el paso de vehículos, etc.). Los zorros en hábitats naturales presentaron respuestas de estrés agudo al ser capturados, pero mostraron niveles medios de GC similares entre las zonas de alto y bajo riesgo de depredación, lo que sugiere una adaptación a la presencia de coyotes. Los zorros urbanos no mostraron respuestas agudas cuando fueron atrapados, lo que sugiere adaptación a la presencia de humanos. Las respuestas al estrés basadas en los niveles de GC revelaron que los zorros en hábitats naturales y urbanos están habituados a las principales fuentes de estrés del hábitat al que pertenecen mitigando, de esta manera, el estrés crónico.

Animals have evolved physiological stress responses to deal with social and environmental perturbations such as predation, conspecific agonistic interactions, environmental catastrophes, and food shortages (Wingfield et al. 1998). When an animal perceives a stressor, the hypothalamus signals the anterior pituitary to release adrenocorticotropic hormone, which in turn signals the adrenal cortex to release glucocorticoid (GC) steroid hormones to help the animal mediate the stressor (Sapolsky 2002, Wingfield and Sapolsky 2003). The release of GC elicits a series of short-term physiological responses including immune and reproductive system suppression, increased blood glucose, and redirection of energy in order to facilitate behavioral responses such as the "fight-or-flight" response (Wingfield et al. 1998, Sapolsky et al. 2000). Wingfield et al. (1998) describe this GC-mediated response as the "emergency life history state."

If the stressor is resolved, GC levels quickly return to baseline levels through a negative feedback loop directly controlled by the elevated GC levels themselves, and the GCaffected behavioral and physiological responses of the animal return to their previous state (Wingfield et al. 1998, Sapolsky et al. 2000). However, if animals have chronically elevated GC levels, resulting from prolonged exposure to stressors, this negative feedback loop may become impaired (Sapolsky et al. 2000). The basal GC levels in animals experiencing chronic stress responses remain high and weaken

\footnotetext{
${ }^{1}$ California State University-Stanislaus, Endangered Species Recovery Program, One University Circle, Turlock, CA 93389

${ }^{2}$ Department of Ecology, Montana State University, 310 Lewis Hall, Bozeman, MT 59715.

${ }^{3}$ Corresponding author. E-mail: bcypher@esrp.csustan.edu
} 
acute stress responses to short-term stressors (Romero 2004). Chronically elevated levels of GCs can have deleterious effects, including reproductive and immune system suppression, ulcers, impaired growth, and muscular atrophy (Sapolsky et al. 2000, Sapolsky 2002). In some cases, the effects of chronically elevated GC levels could be fatal (Wingfield et al. 1998, Wingfield 2005) and thus are of special concern in threatened or endangered species.

We analyzed fecal GC (fGC) levels among San Joaquin kit foxes (Vulpes macrotis mutica) to assess their response to urban environments and to variation in predation risk in natural environments. San Joaquin kit foxes are an endangered subspecies endemic to the San Joaquin Valley of central California, and persist in small populations threatened by continuing habitat loss (USFWS 1998, Cypher et al. 2013). Two of the largest remaining populations are in the Lokern Natural Area (natural habitat) and the city of Bakersfield (urban habitat; USFWS 1998). Primary causes of death are larger predators (mostly coyotes; Canis latrans) for foxes in natural habitats (Disney and Spiegel 1992, Ralls and White 1995, Cypher and Spencer 1998, Nelson et al. 2007) and vehicles (48\%), predation (domestic dogs, coyotes; $30 \%$ ), and rodenticides $(7 \%)$ for foxes in urban habitats (Bjurlin et al. 2005, Cypher 2010).

In Bakersfield, virtually no natural habitat is present and foxes primarily use areas such as school campuses, parks, commercial and industrial areas, golf courses, canals, and storm-water drainage basins (Bjurlin et al. 2005, Cypher 2010). Thus, they occur in close proximity to humans and anthropogenic activities. In the Lokern Natural Area, some areas have dense shrub cover (primarily desert saltbush, Atriplex polycarpa) while other areas are virtually devoid of shrubs, primarily due to repeated wildfires. Coyotes are closely associated with shrubs and as a result, predation on foxes is greater in areas with shrubs, compared to areas without shrubs (Nelson et al. 2007). Consequently, kit foxes with home ranges encompassing greater proportions of shrubland have lower survival rates than foxes residing in areas without shrubs (Nelson et al. 2007). Kit foxes actively avoid coyotes, suggesting that they perceive the predation risk associated with coyotes (Nelson et al. 2007). However, despite the increased predation risk associated with shrublands, kit foxes continue to enter these areas, presumably to forage for their preferred prey species, Heermann's kangaroo rats (Dipodomys heermanni), which are closely associated with shrub habitats (Nelson et al. 2007).

Constant stressors, such as frequent encounters with predators or with humans and their activities, might lead to "permanent perturbations" (Wingfield et al. 1998) that could result in chronic stress responses in kit foxes. In turn, chronic elevation of basal GC levels may prevent foxes from mounting acute GC responses to short-term stressors. We hypothesized that foxes in urban environments would have higher basal fGC levels than foxes in natural environments, based on exposure to human disturbance. We also tested for differences in the strength of acute stress response in each population by comparing the fGC levels of trapped foxes and nontrapped foxes. Then, using data only for Lokern foxes, we tested the hypothesis that basal fGC levels were elevated among foxes using habitats with high predation risk (i.e., shrubland). Our objective was to determine if we could detect potential harmful effects on kit foxes living in anthropogenically disturbed and high-predation-risk environments.

\section{Methods}

\section{Study Areas}

Both the natural and urban study areas are located in Kern County in central California. The natural site, the Lokern Natural Area, encompassed approximately $100 \mathrm{~km}^{2}$ located $60 \mathrm{~km}$ west of Bakersfield, California. Much of the region is alluvial and topography is flat to very gently sloping. The habitat is dominated by saltbush scrub with sparse ground cover consisting primarily of nonnative grasses. Large portions of the area are devoid of shrubs due to repeated wildfires; saltbush is not fire-adapted and fire frequency has increased due to the nonnative grasses. The Lokern Natural Area is primarily a conservation area. Human activity is limited and consists of pockets of oil and gas extraction, hazardous waste processing, and sheep grazing in spring.

The urban site encompassed approximately $100 \mathrm{~km}^{2}$ in the southwestern portion of the city of Bakersfield, California. In stark contrast to Lokern, Bakersfield is a developed urban 
environment with almost no remaining natural habitat. The human population of Bakersfield during this study was approximately 280,000 people. Land uses in the study area included residential neighborhoods, commercial and industrial areas, golf courses, school campuses, canals, railroad rights-of-way, and storm-water drainage basins.

Both study sites have Mediterranean climates with hot, dry summers and cool, wet winters. Annual mean minimum and maximum temperatures were $2{ }^{\circ} \mathrm{C}$ and $36{ }^{\circ} \mathrm{C}$, respectively. Annual precipitation ranged from 5.0 $\mathrm{cm}$ to $15.0 \mathrm{~cm}$ and mostly fell from October through April (NOAA 1996, 2002).

\section{Fecal Collection and Hormone Extraction}

During January 2003-June 2004, we collected 284 San Joaquin kit fox scats for GC analysis. To assess basal GC levels, we opportunistically collected scats from atop small mammal traps, within open fox traps, on scent stations, and at fox dens during field activities conducted for other studies. As described previously, predation risk for kit foxes varied between areas with and without shrubs in the natural-land study area (Nelson et al. 2007). To assess the effect of this risk on GC levels, we collected samples from areas with and without shrubs. These areas were extensive, covering many square kilometers (Nelson et al. 2007). We avoided collecting samples located within approximately $1 \mathrm{~km}$ of the shrub-no shrub interface to reduce the probability of samples from foxes that might be using both habitats. More than one sample may have come from a particular fox, but we collected over large areas on both study sites to help reduce the incidence of such duplicates. To ensure that we collected samples within $24 \mathrm{~h}$ of defecation, we only collected scats from sites that we had revisited and cleared the previous day, and those from trapped foxes. To assess acute GC responses, we collected fresh scats from foxes captured in live traps. Traps were set in the evening and checked the next morning. San Joaquin kit foxes were captured and handled in accordance with protocols established in a research permit (TE825573-2) from the U.S. Fish and Wildlife Service and a Memorandum of Understanding from the California Department of Fish and Game, and we further adhered to National Institutes of Health standards for the care of animals.
We stored all fecal samples in 5-mL screw cap tubes marked with date, time of collection, time of defecation (if known), and location. We placed samples in a cooler in the field during hot months, immediately stored them in a -20 ${ }^{\circ} \mathrm{C}$ freezer upon returning from the field, and logged the time of freezing to record lag time between collection and freezing. Lag times between defecation, collection, and freezing, and the water content of samples (see below) were tested as covariates in statistical analyses.

We extracted steroid hormones using methods in Creel et al. (2002). We homogenized samples manually using a small metal spatula, and then dried fecal samples in a rotary evaporator without heat, weighing all samples before and after drying to determine water content of the feces. We weighed a sample (ca. 0.18-0.22 g) of dried feces to the nearest $0.01 \mathrm{~g}$ using an analytic balance, and boiled this known mass of dry feces in $10 \mathrm{~mL}$ of $95 \%$ ethanol for $20 \mathrm{~min}$. After boiling, we centrifuged the mixture, decanted the supernatant with the extracted hormone, and recorded the mass of the saturated pellet after decanting (again using an analytic balance) before discarding. We evaporated the decanted ethanol and reconstituted the hormone in 5 $\mathrm{mL}$ of ethanol by vortexing for $15 \mathrm{~s}$ and placing the sample in an ultrasonic glass cleaner for $15 \mathrm{~s}$. We repeated the evaporation process and finally reconstituted the hormone in $1 \mathrm{~mL}$ of $100 \%$ methanol, vortexed it for $1 \mathrm{~min}$, and placed it in an ultrasonic glass cleaner for $30 \mathrm{~s}$. We then transferred each extract into 1 -mL cryovials and froze them at $-20^{\circ} \mathrm{C}$ until analysis.

\section{Glucocorticoid Measurement}

We measured cortisol concentrations using enzyme-linked immunoassay kits from R\&D Systems (Minneapolis, MN) that we validated for San Joaquin kit fox fecal extract using standard procedural validation tests for accuracy, specificity, and precision. We prepared all reagents and hormones according to the $R \& D$ instruction manual. We determined the optimal dilution by assaying a series of twofold dilutions, ranging from undiluted extract to a 2048-fold dilution. A 10-fold dilution fell in the steepest part of the standard curve, producing the most sensitive results. To determine the interassay $\mathrm{CV}$ and as a quality control, we created a control sample consisting 
of equal volumes of 10 random samples. This control was assayed in duplicate on all microplates.

Mean $( \pm \mathrm{SE})$ recovery of cortisol added to the pooled control sample (range 0.312-5.0 ng), averaged over 2 assays, was $90.75 \% \pm 7.28 \%$ (nanograms of cortisol measured $=0.85 \times$ nanograms of cortisol added $-0.117 ; R^{2}=0.99, P$ $<0.01)$. The slopes of linear regressions fit to dilution series for known cortisol standards and fox fecal extracts did not differ $\left(F_{1,13}=\right.$ $1.42, P=0.25)$. Cross-reactivity of the assay was low, reporting high affinity for cortisol and cortisol metabolites and $<4 \%$ for all other steroids. The intra- and interassay CVs were $6.7 \%$ and $13.4 \%$, respectively. We excluded values from samples with $\mathrm{CV}$ values over $50 \%$ $(n=9)$ from all statistical analyses and from the determination of CVs.

We used analysis of variance to test for differences in GC concentrations between natural-land foxes in areas with and without shrubs, and $t$ tests to assess GC differences between trapped and nontrapped foxes, as well as to determine differences in water concentrations between rural and urban foxes. We used analysis of covariance to test for differences in GC concentrations between rural and urban foxes, while controlling for differences in water concentrations between the populations. All of the GC concentrations were logtransformed to normalize data, and all GC results are expressed as means $\pm 1 \mathrm{SE}$ of nanograms cortisol per gram dry feces. Water concentrations are expressed as percentage of water, by mass, in the fecal samples.

\section{RESULTS}

Fecal water concentrations were significantly higher $(t=2.43, \mathrm{df}=269, P=0.02)$ among urban foxes $(36.47 \pm 2.23 ; n=63)$ than among rural foxes $(29.95 \pm 1.31 ; n=$ 208). After controlling for these differences, mean fGC level for nontrapped foxes was significantly higher $\left(F_{1,208}=15.01, P<0.01\right)$ among urban foxes $(5.29 \pm 2.15 ; n=32)$ than among rural foxes $(4.69 \pm 0.54 ; n=179)$. Within the urban population, there was not a significant difference $(t=0.10, \mathrm{df}=61, P=$ $0.92)$ in mean fGC level between trapped foxes $(6.04 \pm 3.27 ; n=31)$ and nontrapped foxes (5.29 $\pm 2.15 ; n=32$ ). However, within the rural population, mean fGC level was significantly higher $(t=-4.78$, df $=206, P<0.01)$ for trapped foxes $(64.92 \pm 55.48 ; n=29)$ than for nontrapped foxes $(4.69 \pm 0.54 ; n=179)$. The significant difference in mean fGC level between the rural trapped and nontrapped foxes demonstrated that our methodology was capable of detecting acute, short-term stress responses in kit foxes. We did not detect a significant difference $\left(F_{1,176}=2.81, P=0.10\right)$ in mean fGC level between natural-land kit foxes in areas with $(4.97 \pm 0.70 ; n=33)$ and without shrubs $(4.63 \pm 0.64 ; n=146)$.

\section{Discussion}

Although more samples were obtained for the rural population than for the urban population, we considered our sample sizes to be sufficiently robust to detect differences between populations. Urban foxes had significantly higher mean basal fGC levels compared to foxes in the natural habitat. However, the significance of the higher basal GC levels among urban foxes is unclear. Higher levels could be indicative of chronic stress, which could inhibit the ability of foxes to mount an acute stress response. Such a scenario is consistent with the fact that urban foxes did not exhibit acute stress responses to trapping, which generally is a stress-inducing event for animals. Chronic stress potentially could result in deleterious physiological effects in the urban population.

However, the mean basal fGC level for urban foxes was only 1.13 times higher than that for foxes in natural habitat. This potentially could have resulted from a couple of exceptionally high levels recorded among urban samples. Furthermore, the distributions of fGC levels in natural and urban populations were similar, with the majority of urban foxes having relatively low basal fGC levels (Fig. 1). Also, if the GC response system of urban foxes was impaired due to prolonged exposure to chronic stressors, then urban foxes actually would be expected to have lower basal GC levels than rural foxes. Finally, urban kit foxes do not exhibit any evidence of deleterious effects. They actually have higher survival and reproductive rates than foxes in natural habitat (Cypher 2010). Other than elevated cholesterol levels (attributable to a high proportion of anthropogenic foods in their diet (Newsome et al. 2010), hematological and serological values were similar for foxes in urban and natural 


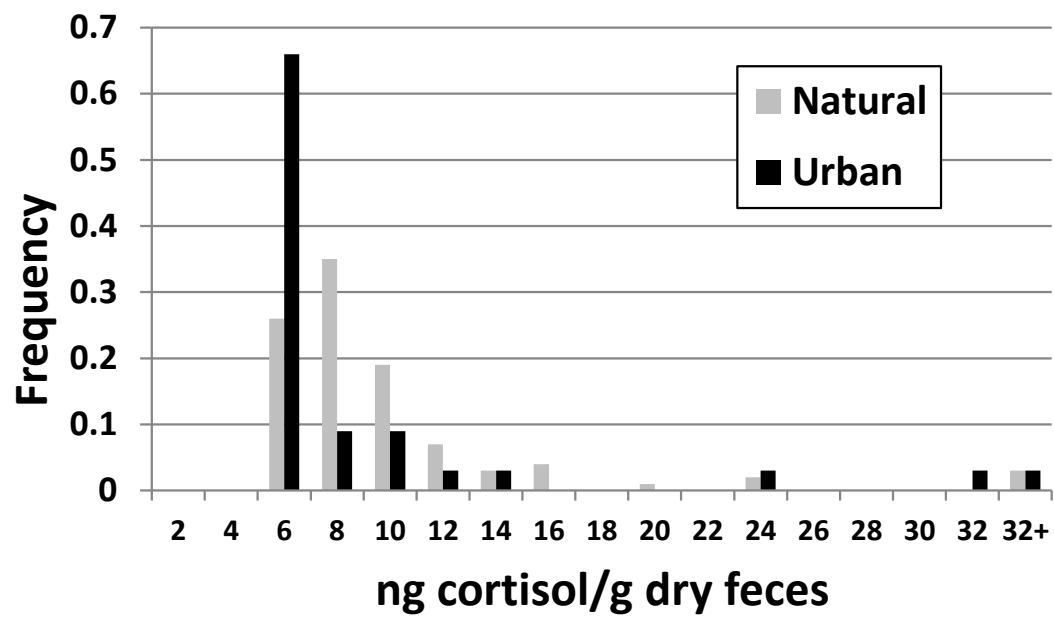

Fig. 1. Distribution of basal cortisol concentrations in kit foxes (Vulpes macrotis mutica) from natural (Lokern Natural Area; $n=179$ ) and urban (city of Bakersfield; $n=32$ ) habitats in California during 2003-2004. Bins along $x$-axis span 2 ng.

habitats (Cypher and Frost 1999). Also, urban foxes generally are heavier (Cypher and Frost 1999) indicating that muscular atrophy, a potential effect of chronic stress (Sapolsky 2002), is not occurring in the urban population. Elk (Cervus elaphus) in Yellowstone National Park also exhibited no obvious adverse biological or demographic effects despite significantly elevated GC levels attributed to snowmobile activity (Creel et al. 2002).

Thus, a plausible alternate explanation is that the lack of an acute stress response by urban foxes when trapped reflects habituation to humans and anthropogenic disturbances. Urban kit foxes are routinely and consistently exposed to humans and anthropogenic activities since birth. If a potential threat is controllable or predictable, it may not be perceived as a stressor and a stress response will not necessarily be mounted (Levine 2000). Foxes in the urban environment may not perceive humans or their activities as a stressor, and so mounting an acute stress response to human activity may be maladaptive.

Kit foxes in the natural habitat also did not appear to be chronically stressed. Coyotes are abundant in the natural environment and present a significant threat to kit foxes (Cypher 2003), and it seems reasonable that foxes would perceive the presence of coyotes as a stressor. However, because exposure to coyotes is constant and because kit foxes have adapted strategies for coexisting with coyotes (e.g., year-round den use; Cypher 2010), the mere presence of coyotes probably is not sufficient to elicit a stress response. Furthermore, we detected no difference in GC levels between foxes using areas with and without shrubs. Coyotes on the study site favored areas with shrubs, and predation risk indeed appeared higher in these areas (Nelson et al. 2007). However, this elevated risk may not have been sufficient to produce a difference in mean fGC level. In essence, foxes in natural habitat likely are habituated to the presence of coyotes, similar to the habituation of urban foxes to humans. Consequently, the stress response system of foxes in natural habitat does not appear to be impaired, and they are able to mount a strong acute stress response as indicated by the significantly elevated levels among trapped foxes.

Our results suggest that foxes in natural as well as urban habitats are well adapted behaviorally and physiologically to their respective environments. Individual foxes likely experience occasional acute stress responses during events such as pursuit by a coyote in the natural habitat or close encounters with domestic dogs or vehicles in the urban habitat. However, chronic stress was not evident in either population, based on fGC levels. Short-term stress potentially may be a detrimental factor for kit foxes under certain circumstances. Stress may have contributed to a canine distemper outbreak among desert kit foxes (Vulpes macrotis arsipus) at a solar energy site being 
constructed in the Mojave Desert (D. Clifford, California Department of Fish and Wildlife, personal communication). Solar energy developments also are occurring within San Joaquin kit fox habitat. Investigations of GC levels and demographic patterns (e.g., reproductive success) in kit foxes before and during such disturbances would help determine whether such developments may be causing physiological impairment and adversely affecting local kit fox populations.

\section{ACKNOWLEDGMENTS}

Funding was provided by the Central Valley Project Conservation Program, United States Fish and Wildlife Service, California Department of Transportation, California Department of Fish and Game, Center for Natural Lands Management, and United States Bureau of Reclamation. We thank the following individuals for all of their assistance on this project: C. Bjurlin, S. Bremner-Harrison, A. Brown, J. Brown, S. Harrison, J. Murdoch, E. Tenant, C. Van Horn Job, J. Valenzuela, and C. Wingert. We also thank 2 anonymous reviewers for helpful suggestions that improved the manuscript.

\section{Literature Cited}

Bjurlin, C.D., B.L. Cypher, C.M. Wingert, and C.L. VAN HoRn Job. 2005. Urban roads and the endangered San Joaquin kit fox. California State University-Stanislaus, Endangered Species Recovery Program, Fresno, CA.

Creel, S., J.E. Fox, A. Hardy, J. Sands, B. Garrott, and R.O. Peterson. 2002. Snowmobile activity and glucocorticoid stress responses in wolves and elk. Conservation Biology 16:809-814.

Cypher, B.L. 2003. Foxes. Pages 511-546 in G.A. Feldhamer, B.C. Thompson, and J.A. Chapman, editors, Wild mammals of North America: biology, management, and conservation. 2nd edition. Johns Hopkins University Press, Baltimore, MD.

2010. Kit foxes. Pages 49-60 in S. Gehrt, S. Riley, and B. Cypher, editors, Urban carnivores: ecology, conflict, and conservation. Johns Hopkins University Press, Baltimore, MD.

Cypher, B.L., And N. Frost. 1999. Condition of San Joaquin kit foxes in urban and exurban habitats. Journal of Wildlife Management 63:930-938.

Cypher, B.L., S.E. Phillips, and P.A. Kelly. 2013. Quantity and distribution of suitable habitat for endangered San Joaquin kit foxes: conservation implications. Canid Biology and Conservation 16:25-31.
Cypher, B.L., And K.A. Spencer. 1998. Competitive interactions between coyotes and San Joaquin kit foxes. Journal of Mammalogy 79:204-214.

Disney, M., AND L.K. Spiegel. 1992. Sources and rates of San Joaquin kit fox mortality in Western Kern County, California. Transactions of the Western Section of the Wildlife Society 28:73-82.

LEVINE, S. 2000. Influence of psychological variables on the activity of the hypothalamic-pituitary-adrenal axis. European Journal of Pharmacology 405:149-160.

Nelson, J., B.L. Cypher, C.D. Bjurlin, and S. Creel. 2007. Effects of habitat on competition between kit foxes and coyotes. Journal of Wildlife Management 71:1467-1475.

Newsome, S., K. Ralls, C. Van Horn Job, M. Fogel, and B. Cypher. 2010. Stable isotopes evaluate exploitation of anthropogenic foods by the endangered San Joaquin kit fox (Vulpes macrotis mutica). Journal of Mammalogy 91:1313-1321.

Ralls, K., and P.J. White. 1995. Predation on San Joaquin kit foxes by larger canids. Journal of Mammalogy 76:723-729.

Romero, L.M. 2004. Physiological stress in ecology: lessons from biomedical research. Trends in Ecology and Evolution 19:249-255.

SAPOLSKY, R.M. 2002. Neuroendocrinology of the stressresponse. Pages 287-324 in J.B. Becker, S.M. Breedlove, D. Crews, and M.M. McCarthy, editors, Behavioral endocrinology. 2nd edition. The MIT Press, Cambridge, MA.

SAPOlsky, R.M., L.M. Romero, and A.U. Munck. 2000. How do glucocorticoids influence stress responses? Integrating permissive, suppressive, stimulatory, and preparative actions. Endocrine Reviews 21:55-89.

[USFWS] United States Fish and Wildlife Service. 1998. Recovery plan for upland species of the San Joaquin Valley, California. U.S. Fish and Wildlife Service, Portland, OR.

[NOAA] United States National Oceanic and AtmosPHERIC ADMINISTRATION. 1996. Local climatological data, Bakersfield, California. National Climatological Data Center, Asheville, NC. 2002. Local climatological data, Buttonwillow, California. National Climatological Data Center, Asheville, NC.

WingFieLD, J.C. 2005. The concept of allostasis: coping with a capricious environment. Journal of Mammalogy 86:248-254.

Wingfield, J.C., D.L. Maney, C.W. Breuner, J.D. Jacobs, S. LynN, M. Ramenofsky, and R.D. Richardson. 1998. Ecological bases of hormone-behavior interactions: the "emergency life history stage." American Zoologist 38:191-207.

Wingfield, J.C., AND R.M. SAPOLSKY. 2003. Reproduction and resistance to stress: when and how. Journal of Endocrinology 15:711-724.

Received 27 December 2013 Accepted 30 December 2014 